\title{
Differences in self reported morbidity by educational level: A comparison of 11 Western European countries
}

Adriënne E J M Cavelaars, Anton E Kunst, José J M Geurts, Roberta Crialesi, Liv Grötvedt, Uwe Helmert, Eero Lahelma, Olle Lundberg, Jil Matheson, Andreas Mielck, Andreé Mizrahi, Arié Mizrahi, Niels Kr Rasmussen, Enrique Regidor, Thomas Spuhler, Johan P Mackenbach

\begin{abstract}
Study objective-To assess whether there are variations between 11 Western European countries with respect to the size of differences in self reported morbidity between people with high and low educational levels.

Design and methods-National representative data on morbidity by educational level were obtained from health interview surveys, level of living surveys or other similar surveys carried out between 1985 and 1993. Four morbidity indicators were included and a considerable effort was made to maximise the comparability of these indicators. A standardised scheme of educational levels was applied to each survey. The study included men and women aged 25 to 69 years. The size of morbidity differences was measured by means of the regression based Relative Index of Inequality.
\end{abstract}

Main results-The size of inequalities in health was found to vary between countries. In general, there was a tendency for inequalities to be relatively large in Sweden, Norway, and Denmark and to be relatively small in Spain, Switzerland, and West Germany. Intermediate positions were observed for Finland, Great Britain, France, and Italy. The position of the Netherlands strongly varied according to sex: relatively large inequalities were found for men whereas relatively small inequalities were found for women. The relative position of some countries, for example, West Germany, varied according to the morbidity indicator.

Conclusions-Because of a number of unresolved problems with the precision and the international comparability of the data, the margins of uncertainty for the inequality estimates are somewhat wide. However, these problems are unlikely to explain the overall pattern. It is remarkable that health inequalities are not necessarily smaller in countries with more egalitarian policies such as the Netherlands and the Scandinavian countries. Possible explanations are discussed.

(F Epidemiol Community Health 1998;52:219-227)
Many studies throughout Europe have reported a higher level of morbidity and mortality for people with a lower educational level, occupational status or income level. ${ }^{1-3}$ An interesting question is whether the size of these health inequalities varies substantially between countries. One of the reasons for studying international variations in socioeconomic inequalities is that international comparison enables judgements to be made on the size of inequalities in health in different country. In addition, comparative studies of health inequalities in societies that differ with respect to the size of income inequalities, national living standards, and other potentially relevant aspects, may shed more light on the causes of socioeconomic inequalities in health.

Several international comparisons have focused on socioeconomic inequalities in self reported morbidity. These studies suggested that the size of inequalities in health varies between countries. ${ }^{4-15}$ Comparative research has, however, until now lacked comprehensiveness and often suffered from problems with comparability of data. More specifically, previous international studies mainly concerned a few countries, especially the Scandinavian countries and Great Britain, and most of them included only one indicator of morbidity. In the few more comprehensive studies ${ }^{914}$ the comparability of the morbidity indicators as well as the socioeconomic indicators was not always optimal.

In this paper, a more comprehensive view of international variations in socioeconomic inequalities in morbidity is given. As well as the four Scandinavian countries and Great Britain, we included the Netherlands, Germany, France, Switzerland, Italy, and Spain. The inclusion of a broad range of countries is informative because comparison of more varied types of societies could provide new insight into the sensitivity of socioeconomic inequalities within different societal contexts. Several different indicators of morbidity were included to cover various aspects of people's health. In addition, this study paid considerable attention to optimising the comparability of the data of the morbidity indicators and the socioeconomic indicator, educational level. Finally, for most countries more recent data, from the early nineties, were used.

The study is part of a larger project called "Socio-economic inequalities in morbidity and mortality in Europe: A comparative study." ${ }^{\prime 6}$ 
Table 1 Surveys included in the study

\begin{tabular}{|c|c|c|c|c|c|c|}
\hline Country & Year & Name & $\begin{array}{l}\text { Number of } \\
\text { respondents }\end{array}$ & $\begin{array}{l}\text { Excluded } \\
\text { subpopulation }\end{array}$ & $\begin{array}{l}\text { Non-response rate } \\
(\%)\end{array}$ & $\begin{array}{l}\text { Proxy } \\
\text { interviews }\end{array}$ \\
\hline Denmark & $1986 / 87$ & Danish Health and Morbidity Survey & 4753 & $\mathrm{~F}$ & 20 & No \\
\hline Finland & 1986 & Survey on Living Conditions & 12057 & I & 13 & No \\
\hline France ${ }^{\star}$ & $1991 / 92$ & Enquête sur la Santé et les Soins Medicaux & 21586 & I & 17 & Noł \\
\hline \multirow[t]{3}{*}{ Germany† } & $1984 / 1986$ & Life and Health in Germany (NHS) & 4790 & $\mathrm{~F}$ & 34 & No \\
\hline & $1987 / 1988$ & Life and Health in Germany (NHS) & 5335 & $\mathrm{~F}$ & 29 & No \\
\hline & $1990 / 1991$ & Life and Health in Germany (NHS) & 5311 & $\mathrm{~F}$ & 31 & No \\
\hline Great Britain & 1991 & General Household Survey & 19039 & I & 15 & Yes $₫$ \\
\hline Italy & $1990 / 91$ & Multiple Household Survey & 132264 & I & 11 & Yes \\
\hline Netherlands & $1991 / 92$ & Health Survey & 11126 & I & 43 & Yes \\
\hline Norway & 1985 & Health Survey & 10600 & I & 21 & No \\
\hline Spain & 1987 & National Health Interview Survey & 27533 & I & 10 & No \\
\hline Sweden & 1991 & Swedish Level of Living Survey & 5306 & & 21 & Yes $\$$ \\
\hline Switzerland & $1992 / 93$ & Swiss Health Survey & 15288 & I & 29 & Yes $\sqrt{3}$ \\
\hline
\end{tabular}

$\mathrm{F}=$ exclusion of foreigners. $\mathrm{I}=$ exclusion of institutionalised persons.

*The question on the morbidity indicator included in this study was only asked to a subsample of the total number of respondents ( $\mathrm{n}=8235)$, $\nmid$ The surveys only referred to the western part of Germany, the former FRG. $\ddagger$ Proxy interviews were used in this survey, but not for the measurement of the morbidity indicator included in this study. \$The percentage of proxy interviews for persons aged $25-69$ was smaller than $5 \%$.

\section{Methods}

DATA SOURCES AND STUDY POPULATION

Data were obtained from national health surveys, level of living surveys or other similar national surveys. In this paper, only surveys with more than 4000 respondents were included. Table 1 gives an overview of the countries included, their surveys and the basic characteristics of each survey. Extensive evaluations were made of the extent to which differences in survey characteristics could have biased the international pattern observed in this study. ${ }^{16}$ The results of these evaluations are summarised in the discussion section.

The analyses were restricted to noninstitutionalised men and women aged 25 to 69 years because this section of the population was included in all surveys. The institutionalised population could not be excluded in Germany. However, because the number of institutionalised persons in this age groups was very small $(<1.5 \%)$ in all countries, ${ }^{16}$ the inclusion or exclusion of this subpopulation probably did not affect inter-country comparisons of inequality estimates.

MEASUREMENT OF MORBIDITY

In this study, four indicators of morbidity were included, which together covered various aspects of a respondent's health. In table 2 the exact definitions of the indicators and the number of countries for which the indicators were available are given.

Perceived general health was mostly measured by a question very similar to "How would

Table 2 Morbidity indicators included in the study and the number of countries for which the indicator was available in a comparable way

\begin{tabular}{|c|c|c|}
\hline Morbidity indicator & Number of countries & Measure of ill health: $\%$ of respondents who ... \\
\hline Perceived general health & 11 & $\begin{array}{l}\text { consider their present state of health less } \\
\text { than good }\end{array}$ \\
\hline Long term disabilities & 6 & $\begin{array}{l}\text { mention one or more long term disabilities } \\
\text { ( } 6 \text { items: climbing stairs, walking, carrying } 5 \\
\mathrm{~kg} \text {, reading newspaper, conversation with } \\
\text { more than } 2 \text { persons, un-/dressing) }\end{array}$ \\
\hline Chronic conditions & 4 & $\begin{array}{l}\text { mention to have suffered from one or more } \\
\text { chronic conditions in the last } 12 \text { months ( } 9 \\
\text { conditions: cancer, diabetes mellitus, } \\
\text { respiratory diseases, heart diseases, stroke, } \\
\text { liver/gall diseases, kidney/urinary tract } \\
\text { diseases, stomach/duodenum ulcer, } \\
\text { muskuloskeletal diseases) }\end{array}$ \\
\hline $\begin{array}{l}\text { Any long standing health } \\
\text { problem }\end{array}$ & 4 & $\begin{array}{l}\text { reply positively to an open question similar } \\
\text { to "Do you suffer from any long standing } \\
\text { illness, disease or disability" }\end{array}$ \\
\hline
\end{tabular}

you judge your present state of health in general?" with five possible response categories varying from very good to very poor. In Britain and Sweden, however, only three response categories were used. In addition, subtle differences were present in the phrasing of the question for different countries; for instance in Spain and Great Britain the question referred to the state of general health over the last 12 months. Because of these differences, "less than good" health might have referred to a more severe health state in one country than in another country. As the observed size of health differences might be related to the severity of the measured health states, for some countries inequality estimates were also calculated for "less than fair" health or another cut off point.

On the basis of an evaluation of the availability and the comparability of the questions on chronic conditions, we decided to include only those surveys in the analyses that used a question in which the respondents have to indicate, for each condition separately, whether they have suffered from the condition during the last 12 months. From the sets of conditions for which data were available in the different countries, we selected nine chronic conditions that together covered a broad spectrum of conditions and that were available for most or all countries. The description of some of the selected chronic conditions was certainly not identical in each survey. However, it was found that the estimates of the magnitude of health differences by education for the total group of nine chronic conditions were not sensitive to the inclusion or exclusion of these specific conditions. ${ }^{16}$

On the basis of an evaluation of the availability and the comparability of the questions on long term disabilities, seven disability items were selected. The selected items, which referred to different aspects of physical functioning, were considered to be fairly comparable and available for at least four countries. One item (can you run 100 metres?) was excluded because it dominated the prevalence rates and because it referred to a clearly less severe form of disability than the other items. We restricted the analysis to those countries for which at least four of the six remaining disabilities were available. Additional analyses showed that the estimates of socioeconomic inequalities in the total 

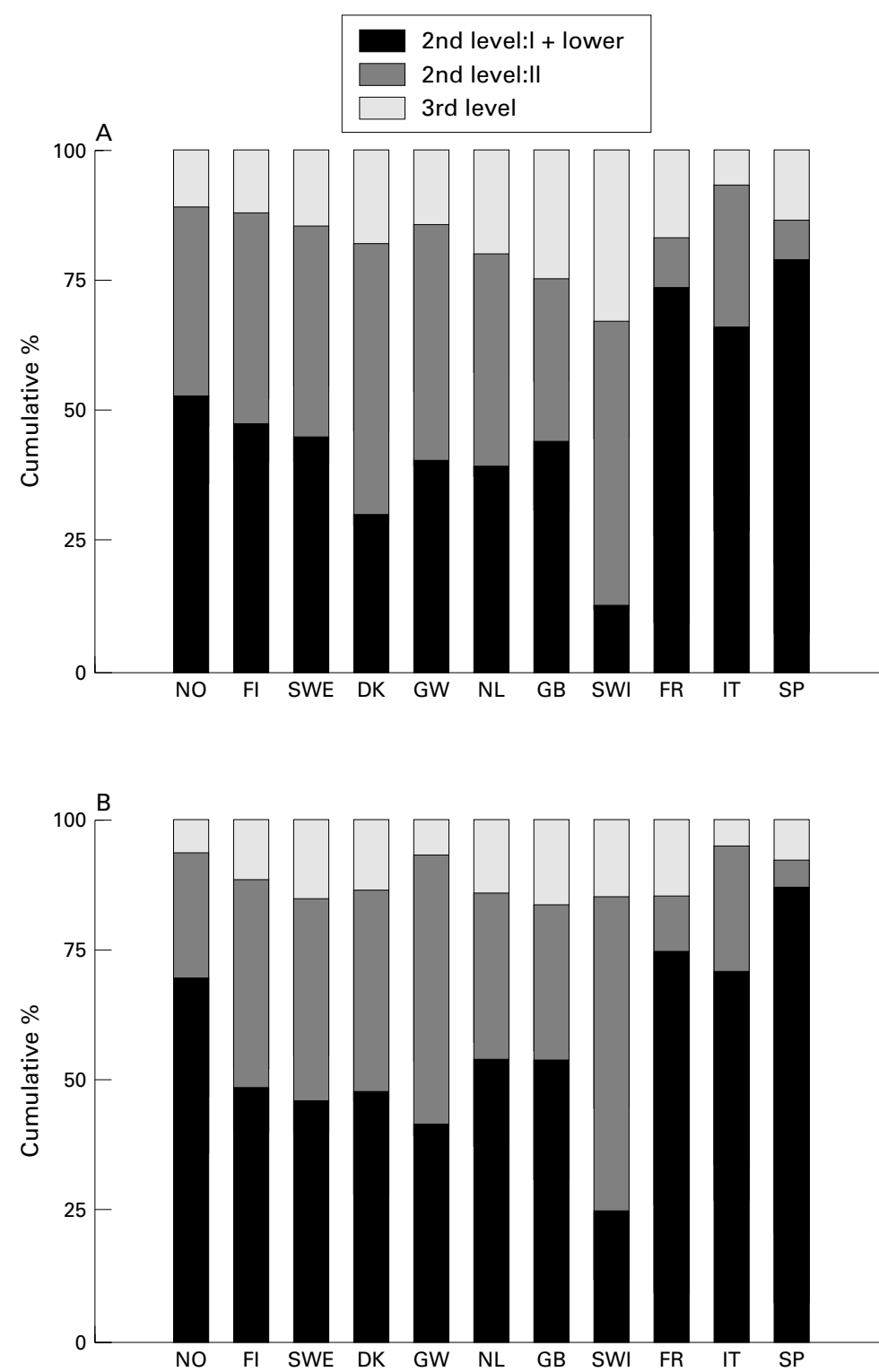

Figure 1 Distribution of the survey population over three educational levels, men $(A)$ and women (B), aged 25 to 69 years.

group of disability items were not sensitive to the inclusion or exclusion of the disabilities that were missing in some of the countries. ${ }^{16}$

The indicator used to elicit any longstanding health problem was based on one straightforward question (see table 2) that did not show substantial differences between countries.

MEASUREMENT OF EDUCATIONAL LEVEL

In all countries, educational level was measured as the highest level of education a person has achieved/completed. In all countries this highest level was based on information on general educational as well as vocational training. The national educational levels were regrouped into five standard hierarchic levels: (1) no education completed, (2) first level (primary school), (3) secondary level (first phase), (4) secondary level (second phase), and (5) third level, which included university and other forms of higher education. ${ }^{17}$

Unfortunately, the available data did not permit us to distinguish for each country the lowest three levels. Therefore, three broad levels were distinguished: third level, secondary level: second phase, and all lower levels.

Figure 1A and 1B show the distribution of the population over these three levels for men and women respectively. The educational distribution of the Scandinavian countries, Denmark, the Netherlands, and Great Britain are fairly similar with the exception of women from Norway who on average have a comparatively low educational level. Although their relatively low education level seems to be an artefact of the available data, no explanation was found for this deviation. The educational distributions in France, Italy, and Spain were more skewed than in other countries. The relatively low percentage of persons belonging to the two highest educational groups in France is caused by the restricted number of persons who complete their educational level with an examination. The deviant educational distribution for Switzerland reflects the particular structure of the educational system in that country, which is characterised by the considerable importance given to part time vocational training. As all persons who followed this type of training are assigned to secondary level (second phase), this level is much larger in Switzerland than in the other countries.

MEASUREMENT OF THE SIZE OF INEQUALITY

The size of morbidity differences between educational groups was measured by means of a regression based index: the Relative Index of Inequality (RII). This index is used earlier to measure socioeconomic health inequalities. ${ }^{14} 18$ It does not only take into account differences in morbidity between educational groups but also the distribution of the population over the educational groups. Advantages of this index are that each educational group is taken into account separately and that only health differences are measured that are systematically related to education.

For the calculation of this index, the socioeconomic status (SES) of each educational group was quantified as the relative position of that group in the educational hierarchy. This continuous measure of SES was related to morbidity rates by means of regression analysis. As the morbidity indicators were defined in a dichotomous way, logistic regression was applied. Adjustment for age was made by including a nominal variable representing five year age groups into the model. Exponentiation of the regression coefficients results in an odds ratio. The interpretation of this measure is the ratio of the odds for having the health problem for those at the bottom of the educational hierarchy as compared with those at the top. More details about this index can be found elsewhere. ${ }^{19}{ }^{20}$

Application of the RII requires the availability of a strictly hierarchical and reasonably detailed educational classification. All countries met the requirement of a hierarchic ordering of educational categories. The second requirement was not completely fulfilled because the lowest three educational groups were combined. This might have biased the results, 
Table 3 The prevalence rate, RII, and 95\% confidence intervals for perceived general health (less than good health, *less than fair health or other cut off point), long term disabilities, chronic conditions, and any long standing health problems, per country. Men, aged 25-69 years

\begin{tabular}{|c|c|c|c|c|c|c|c|c|}
\hline \multirow[b]{2}{*}{ Country } & \multicolumn{2}{|c|}{ Perceived general health } & \multicolumn{2}{|c|}{ Long term disabilities } & \multicolumn{2}{|c|}{ Chronic conditions } & \multicolumn{2}{|c|}{ Long standing health problem } \\
\hline & Prevalence rate & $R I I$ & Prevalence rate & $R I I$ & Prevalence rate & $R I I$ & Prevalence rate & $R I I$ \\
\hline Norway & 21.2 & $6.98(4.55,10.7)$ & 9.6 & $5.40(2.87,10.2)$ & & & & \\
\hline Netherlands & 20.8 & $5.42(4.03,7.29)$ & 8.4 & $5.76(3.67,9.00)$ & 19.5 & $2.51(1.87,3.36)$ & 30.8 & $2.18(1.71,2.78)$ \\
\hline Sweden & 22.0 & $4.84(3.09,7.57)$ & & & 32.1 & $3.87(2.65,5.64)$ & & \\
\hline Denmark & 19.8 & $4.60(2.76,7.66)$ & 7.8 & $2.92(1.36,6.26)$ & & & 31.2 & $2.39(1.57,3.64)$ \\
\hline \multirow[t]{2}{*}{ Finland } & 40.9 & $4.45(3.37,5.88)$ & 17.9 & $3.48(2.40,5.05)$ & & & 42.1 & $2.28(1.74,3.00)$ \\
\hline & $\star 7.4$ & $4.70(2.67,8.29)$ & & & & & & \\
\hline Italy & 20.0 & $4.36(3.79,5.01)$ & & & 24.7 & $3.27(2.89,3.70)$ & & \\
\hline France & 22.1 & $4.23(2.55,7.03)$ & & & & & & \\
\hline \multirow[t]{2}{*}{ Great Britain } & 31.6 & $4.06(3.24,5.10)$ & & & & & 34.0 & $2.09(1.68,2.60)$ \\
\hline & $\star 10.1$ & $4.36(3.01,6.32)$ & & & & & & \\
\hline \multirow[t]{2}{*}{ Switzerland } & 13.2 & $3.09(2.26,4.24)$ & 10.9 & $1.92(1.37,2.70)$ & & & & \\
\hline & $\star 70.7$ & $1.53(1.22,1.92)$ & & & & & & \\
\hline \multirow[t]{2}{*}{ Spain } & 28.8 & $2.74(2.11,3.55)$ & & & 30.4 & $2.12(1.64,2.74)$ & & \\
\hline & $\star 7.2$ & $3.33(1.99,5.59)$ & & & & & & \\
\hline \multirow[t]{2}{*}{ Germany† } & 54.1 & $2.25(1.81,2.79)$ & 13.6 & $3.34(2.01,5.55)$ & 27.9 & $2.39(1.85,3.10)$ & & \\
\hline & ${ }^{\star} 13.7$ & $2.86(2.08,3.93)$ & & & & & & \\
\hline
\end{tabular}

†Data on perceived general health and chronic conditions were obtained from the NHS of 1987/88 and 1990/91; data on long term disabilities were obtained from the NHS of $1984 / 86$.

especially if a large section of the population has attained only lower secondary school or less. This applied to France, Spain, and Italy. Therefore, for these countries we evaluated whether the inequality estimates changed when a further distinction was made within this broad lower group. The results are reported in the next section.

The regression model assumes a linear relation (after logistic transformation) between level of education and the prevalence of a health problem. This assumption was checked for all countries. Non-linearity was observed for Finland only. This non-linearity was characterised by lower than expected morbidity rates in the highest educational group. However, because this highest group was relatively small, this deviation is of minor importance.

\section{Results}

The results will be discussed for men and women separately. Tables 3 and 4 present the prevalence rate and the size of the morbidity inequalities for men and women respectively.

MEN

The prevalence rate of less than good health for men from Denmark, France, Italy, the Nether- lands, Norway, and Sweden is approximately 20 per cent (table 3 ). Relatively high prevalence rates were observed for Finland, Germany, Spain, and Great Britain and a low overall prevalence rate was observed for Switzerland. Differences in overall prevalence might be real or they may be artificial, for example, because of subtle differences in survey questions on perceived general health. In the latter case, less than good health might refer to a more severe health state in one country than in the other. As the size of inequality might be related to the severity of the health problem, the size of inequality was also calculated for a neighbouring cut off point for each of the above mentioned five countries with a deviant overall prevalence rate.

In table 3, the countries are ordered according to the observed size of inequality in perceived general health. The RII for less than good health was largest in Norway, Sweden, the Netherlands, and Denmark while the smallest inequalities were found for Switzerland, Germany, and Spain. The results concerning the neighbouring cut off point for five of the countries showed that a more severe definition of perceived general health results in somewhat larger morbidity inequality estimates. The international position of the five countries was,

Table 4 The prevalence rate, RII, and 95\% confidence intervals for perceived general health (less than good health, less than fair health or other cut off point), long term disabilities, chronic conditions, and any long standing health problems, per country. Women, aged 25-69 years

\begin{tabular}{|c|c|c|c|c|c|c|c|c|}
\hline \multirow[b]{2}{*}{ Country } & \multicolumn{2}{|c|}{ Perceived general health } & \multicolumn{2}{|c|}{ Long term disabilities } & \multicolumn{2}{|c|}{ Chronic conditions } & \multicolumn{2}{|c|}{ Long standing health problem } \\
\hline & Prevalence rate & $R I I$ & Prevalence rate & $R I I$ & Prevalence rate & $R I I$ & Prevalence rate & $R I I$ \\
\hline Sweden & 23.3 & $7.27(4.55,11.6)$ & & & 37.7 & $3.41(2.35,4.95)$ & & \\
\hline Denmark & 22.8 & $6.80(3.95,11.7)$ & 9.3 & $8.81(3.61,21.5)$ & & & 32.6 & $3.59(2.29,5.61)$ \\
\hline Norway & 23.3 & $4.76(2.92,7.73)$ & 12.2 & $4.43(2.23,8.79)$ & & & & \\
\hline France & 30.0 & $4.18(2.82,6.21)$ & & & & & & \\
\hline Great Britain & $\begin{array}{l}37.7 \\
\star \\
\star 11.6\end{array}$ & $\begin{array}{l}4.02(3.24,4.98) \\
3.92(2.76,5.56)\end{array}$ & & & & & 33.7 & $1.82(1.46,2.26)$ \\
\hline Finland & $\begin{array}{l}41.5 \\
\star 6.5\end{array}$ & $\begin{array}{l}3.86(2.93,5.09) \\
3.08(1.72,5.53)\end{array}$ & 19.4 & $3.71(2.57,5.36)$ & & & 42.9 & $2.00(1.53,2.61)$ \\
\hline Netherlands & 22.0 & $3.51(2.59,4.75)$ & 12.1 & $4.45(2.91,6.80)$ & 22.1 & $1.58(1.17,2.13)$ & 29.9 & $1.19(0.92,1.53)$ \\
\hline Spain & $\begin{array}{l}38.7 \\
\star 9.6\end{array}$ & $\begin{array}{l}3.32(2.47,4.46) \\
4.90(2.58,9.33)\end{array}$ & & & 43.0 & $2.00(1.51,2.64)$ & & \\
\hline Italy & 25.6 & $3.14(2.75,3.59)$ & & & 27.1 & $2.42(2.12,2.76)$ & & \\
\hline Switzerland & $\begin{array}{l}15.5 \\
\star 73.5\end{array}$ & $\begin{array}{l}2.72(2.03,3.64) \\
2.81(2.20,3.59)\end{array}$ & 9.7 & $2.12(1.49,3.03)$ & & & & \\
\hline Germanyt & $\begin{array}{l}55.7 \\
\star 15.0\end{array}$ & $\begin{array}{l}2.51(1.99,3.17) \\
2.14(1.56,2.94)\end{array}$ & 19.4 & $4.08(2.59,6.44)$ & 30.3 & $1.56(1.19,2.05)$ & & \\
\hline
\end{tabular}

†Data on perceived general health and chronic conditions were obtained from the NHS of 1987/88 and 1990/91; data on long term disabilities were obtained from the NHS of $1984 / 86$. 
Table 5 The RII and 95\% confidence intervals for less than good perceived health and chronic conditions for France, Italy, and Spain by sex, using 3 or 4 educational levels

\begin{tabular}{|c|c|c|c|c|c|}
\hline \multirow[b]{2}{*}{ Country } & \multirow[b]{2}{*}{ Educational categories } & \multicolumn{2}{|l|}{ Men } & \multicolumn{2}{|l|}{ Women } \\
\hline & & Perceived general health & Chronic conditions & Perceived general health & Chronic conditions \\
\hline \multirow[t]{2}{*}{ France } & 3 & $4.23(2.55,7.03)$ & & $4.18(2.82,6.21)$ & \\
\hline & 4 & $3.53(2.39,5.21)$ & & $3.62(2.66,4.93)$ & \\
\hline \multirow[t]{2}{*}{ Italy } & 3 & $4.36(3.79,5.01)$ & $3.27(2.89,3.70)$ & $3.14(2.75,3.59)$ & $2.42(2.12,2.76)$ \\
\hline & 4 & $4.30(3.84,4.82)$ & $3.15(2.84,3.49)$ & $3.27(2.93,3.65)$ & $2.59(2.32,2.89)$ \\
\hline \multirow[t]{2}{*}{ Spain } & 3 & $2.74(2.11,3.55)$ & $2.12(1.64,2.74)$ & $3.32(2.47,4.46)$ & $2.00(1.51,2.64)$ \\
\hline & 4 & $2.69(2.17,3.35)$ & $2.05(1.66,2.55)$ & $3.53(2.77,4.49)$ & $1.69(1.35,2.13)$ \\
\hline
\end{tabular}

however, not substantially changed by the choice of the alternative cut off point. The RII for countries with a high international position was approximately twice as high as for the countries with a low position. The confidence intervals of the RIIs were very large and only the intervals for the countries at the extreme positions did not overlap.

The percentage of men who mentioned one or more disabilities ranged from 7.8 to 17.9 . A part of this difference was because the number of included disabilities per country ranged from four to six. As is explained in the methods section, the observed size of inequalities in health in a country is probably not largely influenced by the omission of one or two disability items. Inequality estimates were highest for Norway and the Netherlands, followed by Finland and Germany. Small inequalities were observed for Denmark and Switzerland. There were some differences with the international pattern that was observed for less than good health, notably for Germany and Denmark.

For the indicator chronic conditions the prevalence roughly ranged from 20 to 30 per cent. The inequality estimates were highest for men from Sweden, followed by Italy, while the smallest inequalities were found for the Netherlands, Germany, and Spain. Some of the results for this indicator were not in line with the results for less than good health, notably the position of the Netherlands.

The prevalence rate of any longstanding health problem for men from Denmark, Great Britain, and the Netherlands was about 30 per cent or more. Again, a higher prevalence rate was found for Finland. The RII estimates for these countries were not clearly different from each other, and their confidence intervals largely overlapped. This contrasted with the results for perceived general health, for which smaller differences were found for Great Britain than for the Netherlands and the Scandinavian countries.

WOMEN

The results for women, which are shown in table 4, corresponded fairly well to that of men: relatively small inequalities were found for Switzerland, Germany and Spain, and large inequalities for Norway and Sweden. The major differences with the results for men were the relatively small inequalities among women in the Netherlands and the large inequalities among women in Denmark. The international patterns of inequality estimates for the different morbidity indicators were reasonably well in line with each other.

\section{ADDITIONAL ANALYSIS}

Because the percentage of persons belonging to the lowest educational level was very large in France, Spain, and Italy, we evaluated whether the RII estimates changed when the lowest educational group was divided into two hierarchical groups. Table 5 shows the results. For men and women, the changes in inequality estimates for Spain and Italy were negligible. The inequality estimates for men and women in France decreased when more educational categories were distinguished. However, France remained close to the international average.

\section{Discussion}

SUMMARY OF THE FINDINGS

In this paper, morbidity differences according to education were studied for 11 countries from both the northern, western, and southern parts of Europe. For almost all countries, two or more indicators of morbidity were included. Differences were measured using the RII.

The size of morbidity differences was found to vary substantially between countries. There was a tendency for inequalities to be relatively large in Sweden, Norway, and Denmark. Intermediate inequalities were observed for Finland, Great Britain, France, and Italy, and relatively small inequalities were found in Spain, Switzerland, and Germany. However, the international pattern of the size of health inequalities varied between morbidity indicators and between sexes. For example, health inequalities in the Netherlands were found to be relatively large for men but relatively small for women. Another example was that relatively small inequalities were found for less than good health for men and women from Germany whereas intermediate inequalities were found for long term disabilities.

When the RII is used, a larger inequality estimate for one country than for another can be attributed to a larger effect of education level on morbidity or to larger inequalities in educational level in these countries, or both. ${ }^{19}{ }^{20}$ To disentangle these two components, additional analyses were performed (results not shown). The results suggested that the international variations found in this study result from variations between countries in the effect of education on morbidity and not from variations in the size of inequalities in education itself. $^{16}$ 
INTERNATIONAL COMPARABILITY OF THE DATA Much attention was focused on the international comparability of morbidity indicators. Cross national comparisons were only made for morbidity indicators that were highly comparable as judged against the structure and the wording of the respective survey questions. However, some remaining comparability problems could not be avoided. Analyses in which the results were evaluated (for example, evaluation of a different cut off point for perceived general health) suggested that the international positions of countries that were observed in this study were robust. ${ }^{16}$

The surveys included in this study differed in some general characteristics. In table 1 the major survey characteristics that differed between the countries were mentioned. If inequality estimates are sensitive to these survey characteristics, the comparability of the inequality estimates for the different countries will be reduced. Non-response rates bias health inequality estimates if they are related to SES and, given SES, to health status. There are indications that response rates are lower in lower socioeconomic groups and in less healthy people. This could imply that non-response might lead to an underestimation of health inequality estimates. The higher the percentage of non-response the larger this underestimation may be. The same applies to the exclusion of foreigners. Another survey characteristic that might bias the results is the use of proxy interviews. Sensitivity analyses using data from the Dutch survey showed that the use of proxy interviews was related to SES, and that their use might underestimate morbidity levels in persons with a low SES to a larger extent than morbidity levels in persons with a high SES. ${ }^{16} \mathrm{~A}$ final aspect that could affect the results relates to differences in the year when the survey was carried out, which varied between 1985 and 1993. If there is a trend toward increasing inequalities in countries with relatively old surveys, the inequality estimates reported in this study will be smaller than the inequality estimates found if more recent data had been used. For Spain and Norway, which have relatively old surveys, some evidence is available that suggests that inequalities are increasing over time. ${ }^{16}$

The question is whether these differences in survey characteristics might explain some of the international variation in the size of health inequalities, and more specifically the relatively small inequalities in Spain, Germany, and Switzerland that were observed in this study. This indeed cannot completely be excluded. For instance, the size of health inequalities in Switzerland and Germany might have been underestimated because of the relatively high non-response rate and in case of Germany, also because of the exclusion of foreigners, who comprised approximately $8 \%$ of the German population. The size of health inequalities in Spain might have been larger if a more recent survey had been used. On the other hand, there are also surveys with similar general survey characteristics that none the less show large socioeconomic inequalities in morbidity, for example the Dutch and Norwegian surveys.

Taking into consideration the large confidence intervals around inequality estimates and the remaining problems with the comparability of the available data, the exact international position for most countries is uncertain. However, these problems are unlikely to explain the overall pattern, including the finding that egalitarian countries like the Scandinavian countries and the Netherlands do not have smaller inequalities in self reported morbidity than other countries.

This is remarkable because it does not agree with the expectation that these inequalities are smaller in countries with more egalitarian socioeconomic and other policies, such as the Scandinavian countries and the Netherlands. The "Scandinavian welfare model" ${ }^{21}$ resulted in, among others, a high share of state expenditures on social affairs and generous unemployment and disability benefits in the 1980s. ${ }^{22}$ This has contributed to the fact that in the 1980s both the Netherlands and the Scandinavian countries have smaller income inequalities than any other country included in this study. ${ }^{23}$ In addition, disadvantaged population groups in these countries have, as in Great Britain, virtually free access to high quality medical care. ${ }^{9}$ Sweden's egalitarian socioeconomic policies date back to the 1930s, while those in Norway, Denmark, Finland, and the Netherlands were developed in the post-war period. ${ }^{21}$

COMPARISON WITH PREVIOUS INTERNATIONAL STUDIES

The results of previous international comparisons with respect to health inequalities according to educational level partly agree with our study. Lahelma et $a l^{10}{ }^{13}$ compared the size of inequalities in limiting longstanding illness for women and men from Sweden, Norway, and Finland. Interestingly, their comparison was based on the same survey carried out in each of the three countries: the Nordic Level of Living Survey 1986-87 (the Finnish part of that survey is also used in the present study). Using these highly comparable data, Lahelma et al also observed somewhat larger (relative) inequalities for men from Norway and Sweden than for men from Finland. Inequalities among women were largest in Sweden. As in our study, the differences between the Scandinavian countries were small and not statistically significant.

Kunst et $a l^{14}$ compared a broader range of countries using several indicators of morbidity, based for most countries, on national surveys carried out in 1986/87. They observed for men and women approximately the same relative position for the Netherlands, Denmark, and Great Britain as was observed in this study. This is perhaps not surprising because their data for these three countries was elicited from the same surveys, albeit often from an earlier survey year. Other results of their study, however, were not completely in line with our results.

One of the discrepancies relates to the position of Italy and Germany, for which Kunst et al 
observed relatively large health inequalities according to education, rather than the intermediate and small inequalities observed in this study. This discrepancy is probably related to the measurement of morbidity. Kunst et al included only one morbidity indicator for these countries. For Italy, a morbidity indicator was used that indicated whether persons were restricted in their daily activities, such as going to work during the last 14 days. Socioeconomic inequalities detected from this indicator can be strongly determined by (international variation in) exogenous factors such as the economic and social determinants of work absence. In this study, on the other hand, two more general indicators of morbidity were used-that is, perceived general health and the prevalence of chronic conditions. For Germany, Kunst et al used a measure of the prevalence of a few specific long term disabilities. The problem with the use of this indicator was that it had a low prevalence rate, which resulted in very wide confidence intervals around the inequality estimates. In this study, more stable inequality estimates could be made for this indicator and, in addition, two other morbidity indicators.

Another discrepancy related to Sweden, for which Kunst et al found somewhat smaller inequalities than our study showed. Inequalities in Sweden were found to be approximately as large as in Great Britain. In an extensive evaluation we found that the discrepancy was related to the choice of the survey for Sweden: that is, the Survey of Living Conditions from 1981 and 1988 used in the study of Kunst et al, and the Level of Living Survey of 1991, a panel study, used in the present study. After reanalysing the data from these two surveys with precisely the same statistical methods, health indicators and socioeconomic indicators, we found somewhat larger inequality estimates with data from the Level of Living Survey.

In conclusion, the results of previous international comparisons on morbidity differences according to educational level agree only in part with the results of this study. The discrepancies that are observed underline the need to include different morbidity indicators in comparisons between countries. They in addition emphasise that the use of a different survey might lead to somewhat different results for a specific country. For Sweden as compared with Great Britain, larger inequalities were observed in data from the survey used in this study as well as the surveys used by Lahelma et al, but equally large inequalities were observed in the survey used by Kunst et al. It is important to note, however, that despite this uncertainty about Sweden's international position, it cannot be considered low from a wider international perspective.

Some other international comparative studies have used occupational class and income level as indicators of socioeconomic status. As different socioeconomic indicators refer to different aspects of a person's socioeconomic status and vary to the extent in which they are influenced by health, it could be questioned whether the same results would be obtained by using occupation or income as socioeconomic

\section{KEY POINTS}

- In all Western European countries for which data are available, prevalence rates for less than good perceived health, chronic conditions, long term disabilities, and any longstanding illness are found to be higher among lower educated than among higher educated people.

- The size of inequalities in health varied between countries. In general, there was a tendency of inequalities to be relatively large in Sweden, Norway, Denmark, and the Netherlands and relatively small in Spain, Switzerland, and Germany.

- It is remarkable that the Scandinavian countries and the Netherlands do not have relatively small inequalities in morbidity despite a tradition of egalitarian socioeconomic and other policies.

indicators. Only three earlier comparisons focused on inequalities in morbidity according to occupational class. The results of these studies corresponded fairly well with ours on education. ${ }^{6812}$ For example, in a re-analysis of data presented by Vågerö and Lundberg ${ }^{6}$ by Wagstaff et al slightly larger inequalities were found in Sweden compared with Britain. ${ }^{8}$ The international pattern for income seems to be different. Doorslaer et $a l^{15}$ compared nine countries with respect to the size of differences between income groups in perceived general health for men and women combined, using data from national surveys from 1985 to 1992 . For the Netherlands, Great Britain, and Sweden the same survey was used as in this study, although often from an earlier survey year. Relatively large inequalities were reported for Great Britain, intermediate differences for the Netherlands, Finland, Spain, Switzerland, and West Germany and small differences for Sweden and East Germany.

One explanation for the inconsistencies between the international patterns found for the different socioeconomic indicators might be that in countries where large morbidity inequalities according to income exist, material rather than behavioural factors play a larger part. It seems as if egalitarian socioeconomic and other policies in the Nordic countries mainly influenced income related health inequalities and were not equally effective in reducing health differences according to education.

\section{Conclusion}

In contrast with what has been expected, health inequalities are not necessarily smaller in countries with more egalitarian policies, such as the Netherlands and the Scandinavian countries. There is even some evidence that educational inequalities in self reported morbidity are somewhat larger in most Scandinavian countries and the Netherlands. This finding raises the question as to what the reasons might be for the perhaps larger inequalities in these countries. 
A possible explanation that cannot yet be excluded, refers to the subjective nature of the morbidity data included in this study. Self reported data are sensitive to the respondent's perception of "objective" health problems, and their illness behaviour. Socioeconomic inequalities in these factors might partly explain socioeconomic differences in self reported morbidity. ${ }^{24}$ Countries might differ in the extent of inequalities in perceptions of health, and illness behaviours, and this might perhaps explain our finding that inequalities in perceived general health are relatively large in most Scandinavian countries. This does not seem to be probable when taking into consideration our finding that inequalities in long term disabilities, a more objective indicator of morbidity, were also at least as large in the Scandinavian countries and the Netherlands as in other European countries. Nevertheless, the possibility of response bias cannot be excluded. Unfortunately, there is yet very little evidence of the contribution that health perceptions and other psychosocial factors make to inequalities in self reported health in European countries.

Another possible explanation is that countries differ in the amount of social mobility that exists. In more "open" countries, the educational level achieved is less dependent on the socioeconomic status of a person's parents, and more on personal characteristics, including health (direct selection) and health related factors (indirect selection). In this way a larger degree of social mobility can add to larger inequalities in health. Although the different international comparisons of social mobility did not yield consistent results, ${ }^{25}{ }^{26}$ one study convincingly showed that mobility rates were somewhat higher in Sweden than in France and England and Wales. ${ }^{27}$

A final explanation relates to the possibility that countries with relatively large inequalities in morbidity have larger socioeconomic gradients in risk factors for disease, for example, behaviour related factors such as smoking and alcohol consumption. Perhaps specific sociocultural factors have contributed to steeper social gradients in these risk factors in the Netherlands or the Scandinavian countries or to small inequalities or even inverse gradients in Germany, Switzerland or Spain. A recent paper on international variations in the socioeconomic gradients in risk factors observed a north-south pattern for smoking among women, and for heavy smoking among men, with small or even positive associations in France and the Mediterranean countries. $^{28}$

More research is clearly necessary to identify the determinants of the international pattern of health inequalities observed in this study.

Essential for this study was the willingness of the central statistical offices of all participating countries to provide unpublished data from health interview surveys or other national surveys.

The design of the study, the data specifications and the inter-

pretation of preliminary results were discussed at three pretation of preliminary results were discussed at three We want to thank all participants to these workshops for their We want to thank all participants to these
valuable contribution to the discussions.

The views expressed in this paper are those of the authors alone, and do not necessarily reflect the views of their employ- ers, such as the national statistical bureaus of the countries participating in this study.

Funding: this study was supported by a grant from the European Union's Biomed-1 program (CT92-1068).

Conflicts of interest: none.

\section{Appendix}

Department of Public Health, Erasmus University, Rotterdam, the Netherlands: A E J M Cavelaars, A E Kunst, J P Mackenbach; Department of Health Policy and Management, Erasmus University, the Netherlands: A E J M Cavelaars; Statistics Netherlands, Heerlen, the Netherlands: J J M Geurts; National Institute of Statistics, Rome, Italy: R Crialesi; Division for Health, Statistics Norway, Oslo, Norway: L Grötvedt; Centre for Social Policy Research, Bremen University, Bremen, Germany: U Helmert; Department of Public Health, University of Helsinki, Helsinki, Finland: E Lahelma; Swedish Institute for Social Research, Stockholm University, Stockholm, Sweden: O Lundberg; Social Survey Division, Office for National Statistics, London, United Kingdom: J Matheson; GSF- Institute for Medical Informatics and Health Service Research (MEDIS), D - Neuherberg, Germany: A Mielck; CREDES, Paris, France: Andreé Mizrahi, Arié Mizrahi; Danish Institute for Clinical Epidemiology, Copenhagen, Denmark: N Kr Rasmussen; Department of Epidemiology, Ministry of Health, Madrid, Spain: E Regidor; Swiss Federal Statistical Office, Bern, Switzerland: T Spuhler.

1 Illsley R, Svensson PG. Social inequalities in health. Soc Sci Med 1990;31 (special issue):223-40

2 Fox AJ, ed. Health inequalities in European countries. Aldershot: Gover, 1989

3 Mielck A, Rosario Giraldes M, eds. Inequalities in health and health care. Review of selected publications from 18 Western European Countries. Münster: Waxmann, 1993.

4 Karisto A, Notkola V, Valkonen T. Socio-economic status and health in Finland and the other Scandinavian countries. Soc Sci Med 1978;12C:83-8.

5 Lundberg O. Class and health: comparing Britain and Sweden. Soc Sci Med 1986;235:11-17.

6 Vågerö $\mathrm{D}$, Lundberg $\mathrm{O}$. Health inequalities in Britain and Sweden. Lancet 1989;ii:35-6.

7 Lahelma E, Valkonen T. Health and social inequities in Finland and elsewhere. Soc Sci Med 1990;27:257-65.

8 Wagstaff A, Paci P, van Doorslaer E. On the measurement of inequalities in health. Soc Sci Med 1991;33:545-7.

9 van Doorslaer E, Wagstaff A, Rutten F. Equity in the finance and delivery of health care: an international perspective. Oxford: Oxford University Press, 1992.

10 Lahelma E, Manderbacka K, Rahkonen O, Karisto A, Sihvonen A. Ill-health and its social patterning in Finland, Norway and Sweden. Helsinki: National Research and Development Centre for Welfare and Health, 1993.

11 Arber S, Lahelma E. Inequalities in women's and men's illhealth: Britain and Finland compared. Soc Sci Med 1993;37:1055-68.

12 Lahelma E, Arber S. Health inequalities among men and women in constrasting welfare states: Britain and three Nordic countries compared. European fournal of Public Health 1994;4:213-26.

13 Lahelma E, Manderbacka K, Rahkonen O, Karisto A. Comparison of inequalities in health: evidence from national surveys in Finland, Norway and Sweden. Soc Sci Med 1994;38:517-24.

14 Kunst AE, Geurts JJM, van den Berg J. International variation in socio-economic inequalities in self-reported health. $\mathcal{F}$ Epidemiol Community Health 1995;49:117-23.

15 van Doorslaer $\mathrm{E}$, Wagstaff $\mathrm{A}$, Bleichrodt $\mathrm{H}$, et al. ncome-related inequalities in health: some international comparisons. Fournal of Health Economics 1997;16:93-112.

16 Kunst AE, Cavelaars AEJM, Groenhof F, Geurts JJM, Mackenbach JP, EU-Working Group on Socio-economic nequalities in Health. Socioeconomic inequalities in morbidity. and mortality in Europe: a comparative study. Rotterdam: Erasmus University, 1996.

17 OECD. Education in OECD countries 1987-89. A compendium of statistical information. Paris: OECD, 1990.

18 Kunst AE, Mackenbach JP. The size of mortality differences associated with educational level in nine industrialized countries. Am f Public Health 1994;84:932-7. 
19 Kunst AE, Mackenbach JP. Measuring socio-economic inequalities in health. Copenhagen: World Health Organizaequalities in
tion, 1994 .

20 Mackenbach JP, Kunst AE. Measuring the magnitude of socio-economic inequalities in health: an overview of available measures illustrated with two examples from Europe. Soc Sci Med 1997;44:757-71.

21 Esping-Andersen G. Three worlds of welfare capitalism. Oxford: Polity Press, 1990.

22 EUROSTAT. Europe in figures. 4th English ed. Luxembourg. Office for Official Publications of the European Communities, 1995.

23 Atkinson AB, Rainwater L, Smeeding TM. Income distribution in OECD countries. Paris: OECD, 1995.

24 Blane D, Power C, Bartley M. The measurement of morbidity in relation to social class. In: Abel T, Geyer S, Gerhardt
U, eds. Medical sociology: research on chronic illness. Bonn/Berlin: Informationszentrum sozialwissenschaften, 1993:65-84.

25 Treiman DJ, K.B. Y. Educational and occupational attainment in 21 countries. In: Kohn ML, ed. Crossnational research in sociology. Newbury Park: Sage, 1989: 373-94

26 Treiman DJ, Ganzeboom HBG. Comparative research on intergenerational status attainment - a review. Research on Social Stratification and Mobility 1990;9:105-27.

27 Erikson E, Goldthorpe JH. The constant flux. Oxford: Clarendon Press, 1992.

28 Cavelaars AEJM, Kunst AE, Mackenbach JP. Socioeconomic differences in risk factors for morbidity and mortality in the European Community: An international comparison. Fournal of Health Psychology 1997;2:353-72.

\section{$\mathrm{JECH}$ and the world wide web}

Visitors to the world wide web can now access the fournal of Epidemiology and Community Health either through the BMJ Publishing Group's home page (http://www.bmjpg.com) or directly by using its individual URL (http://www.jech.com). There they will find the following:

- Current contents list for the journal

- Contents lists of previous issues

- Members of the editorial board

- Subscribers' information

- Instructions for authors

- Details of reprint services.

Hotlink

A hot link gives access to:

- BMJ Publishing Group home page

- British Medical Association website

- Online books catalogue

- BMJ Publishing Group books.

Suggestions welcome

The website is at a preliminary stage and there are plans to develop it into a more sophisticated site. Suggestions from visitors about features they would like to see are welcomed. They can be left via the opening page of the BMJ Publishing Group site or, alternatively, via the journal page, through "about this site". 